\title{
Short Communication: Simultaneous Identification of Five $\kappa$-Casein (CSN3) Alleles in Domestic Goat by Polymerase Chain Reaction-Single Strand Conformation Polymorphism
}

\author{
S. Chessa, ${ }^{*}$ E. Budelli, $†$ K. Gutscher, $\ddagger$ A. Caroli, $\S$ and G. Erhardtł \\ Dipartimento di Scienze e Tecnologie Veterinarie per la Sicurezza Alimentare, \\ Università degli Studi di Milano, \\ 20134 Milano, Italy \\ †Fondazione Parco Tecnologico Padano, \\ Centro Ricerche e Studi Agroalimentari, \\ 20090 Segrate (Milano), Italy \\ ‡Institut für Tierzucht und Haustiergenetik, \\ Justus-Liebig Universität, \\ 35390 Gießen, Germany \\ $\S$ Dipartimento di Sanità e Benessere Animale, \\ Università di Bari, \\ 70010 Valenzano (Bari), Italy
}

\begin{abstract}
Until now, a total of nine polymorphic sites corresponding to six different alleles have been described at the $\kappa$-casein (CSN3) locus in the domestic goat (Capra hircus). A protocol for the rapid and simultaneous genotyping of five goat CSN3 alleles by using polymerase chain reaction-single strand conformation polymorphism (PCR-SSCP) technique was developed. Moreover, the developed test was validated by screening the CSN3 variability in four Italian breeds, Garganica, Jonica, Maltese, and Camosciata. Seven different patterns were readily identifiable. These corresponded to five known alleles and two newly identified variants. The G/A substitution at nucleotide position 471 , which is not identifiable at the protein level but was found to be very frequent in the typed breeds, is easily detectable by the protocol developed. The PCR-SSCP analysis is a powerful tool for the genetic study of CSN3 variability in domestic goats, allowing both the simultaneous identification of different alleles, and the detection of new variants.
\end{abstract}

(Key words: goat, $\kappa$-casein, genetic polymorphism, single strand conformation polymorphism)

Abbreviation key: CSN3 $=\kappa$-casein locus, IEF $=$ isoelectrofocusing, PCR-SSCP = polymerase chain reaction-single strand conformation polymorphism.

Investigation of milk protein genetic polymorphism started more than $40 \mathrm{yr}$ ago and is still arousing re-

Received March 25, 2003.

Accepted July 17, 2003.

Corresponding author: S. Chessa; e-mail: stefania.chessa@ unimi.it. search interest because of the relationships with milk quality, composition, and technological characteristics (Martin, 1993; Grosclaude et al., 1994). It is well known that CN genes are organized as a cluster (Ferretti et al., 1990; Threadgill and Womack, 1990) including $\alpha_{\mathrm{S} 1^{-}}$ $\mathrm{CN}, \beta$-CN, $\alpha_{\mathrm{S}^{-}} \mathrm{CN}$, and $\kappa$-CN locus (CSN3). Among the $\mathrm{CN}$ fractions, $\kappa$-CN plays an important role in the formation, stabilization, and aggregation of $\mathrm{CN}$ micelles.

Little information was available about genetic variation of caprine CSN3 until 1990, when two variants were described at the protein level (Di Luccia et al., 1990) and named A and B. The occurrence of the B variant was successively confirmed in different breeds (Budelli et al., 2000). The corresponding allele was characterized at the DNA level (Caroli et al., 2001) and compared with the first goat CSN3 nucleotide sequence described (Coll et al., 1993).

Further CSN3 variants were reported by Yahyaoui et al. (2001) and Angiolillo et al. (2002), whereas additional variants have been deposited in GenBank (http:// www.ncbi.nlm.nih.gov) but not published in literature. Table 1 shows the different alleles found in domestic goats and the conflicting nomenclature, especially as it pertains to the $B$ and $D$ variants. A new nomenclature is now proposed based on the order of submission of sequences to GenBank. Moreover, the new nomenclature proposed is also in agreement with the previous literature about goat CSN3 identification at the protein level (Di Luccia et al., 1990) and its characterization at the protein level (Budelli et al., 2000). Mercier et al. (1976a, 1976b) observed a polymorphism in the $\kappa$-CN goat protein sequence, finding a heterozygous animal at the amino acid position 119 (Val//le). The two sequences described correspond to the variants named $A$ and $D$, respectively, in this study. Nevertheless, the authors 
Table 1. $\kappa$-Casein locus (CSN3) nucleotide and amino acid differences among domestic goats. Nucleotide positions are compared with GenBank accession no. X60763. The date of GenBank sequence submission, new and old nomenclature, and reference of the published papers are also reported. Synonymous mutations are in italics.

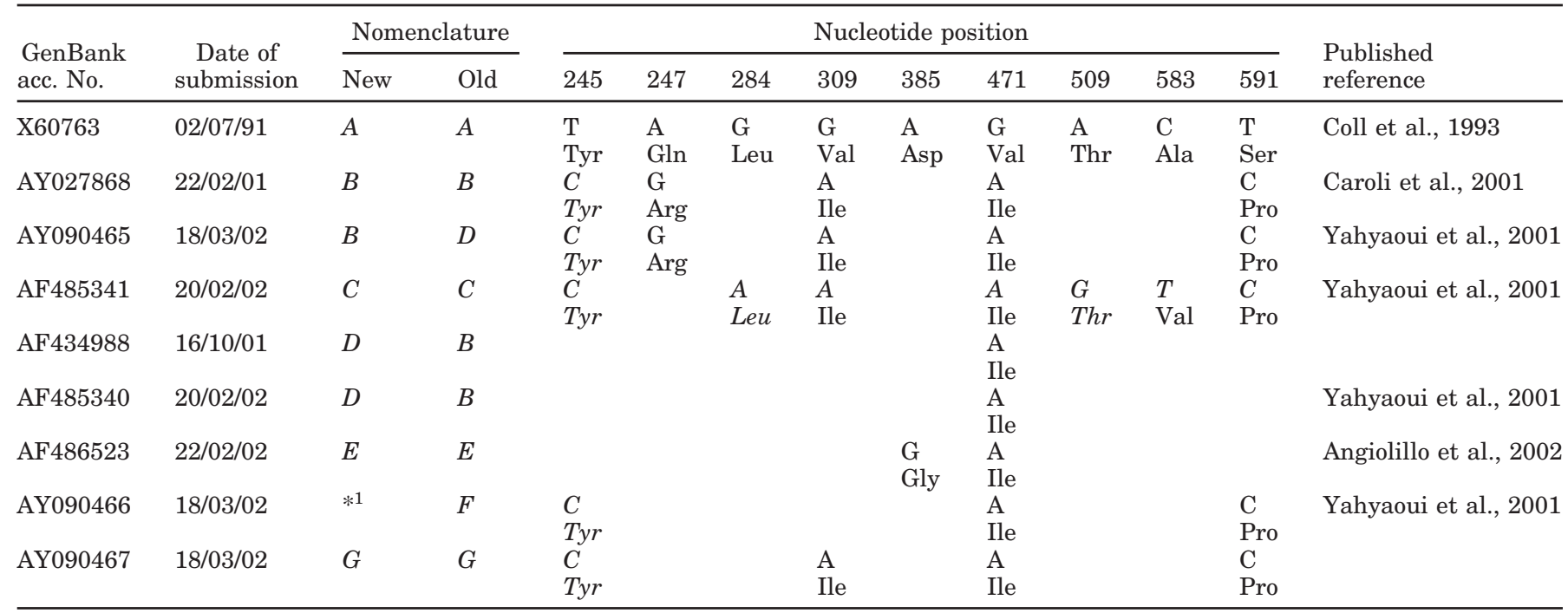

${ }^{1}$ Identified only in wild goat (Capra pyrenaica).

did not propose any nomenclature for the two variants nor perform studies on their genetic transmission.

The new nomenclature will be used in this note to refer to the different variants. The $F$ allele was also described (GenBank accession no. AY090466), but previously it has been found only in wild goat (Capra pyrenaica) (Yahyaoui et al., 2001). Thus, referring to the published sequences, a total of nine polymorphic sites and six DNA alleles, corresponding to six different protein variants, have been identified in domestic goats (Table 1). The importance of developing a molecular method for a complete typing of goat CSN3 variability is evident.

The polymerase chain reaction-single strand conformation polymorphism (PCR-SSCP) method was successfully used for the molecular identification of six protein variants and three additional DNA polymorphisms in bovine CSN3 (Prinzenberg et al., 1999). The same technique was used to distinguish $C S N 3 * A$ from $C S N 3{ }^{*} B$ (Caroli et al., 2001) in domestic goat. To improve the PCR-SSCP method for goat CSN3 genetic analysis, we describe a new PCR-SSCP test and results regarding its application for typing four Italian domestic goat breeds.

Samples. DNA samples sequenced within CSN3 exon $I V$, and corresponding to different genotypes ( $A B$, $B B, B D, C D, D D$, and $E E$ ) were used as references to develop the PCR-SSCP protocol. Moreover, blood and individual milk samples were randomly collected from three Southern Italy goat breeds, Garganica $(n=34)$, Jonica $(n=119)$, and Maltese $(n=105)$; and one Northern Italy breed, Camosciata $(\mathrm{n}=45)$, to validate the developed test. The DNA was extracted from blood by a commercial kit (GFX Genomic Blood DNA Purification Kit, Amersham Biosciences, Piscataway, NJ). The following analyses were performed.

PCR. A 406-bp fragment containing exon IV of the goat CSN3 gene was amplified by PCR, using primers designed on the basis of the caprine sequence GenBank accession no. AY027868. The PCR reaction was performed in a $25-\mu \mathrm{l}$ reaction mixture containing $2 \mu \mathrm{l}$ of DNA solution (10 to $100 \mathrm{ng}$ ), $7 \mathrm{pmol}$ of the primers KCN I F and KCN I R, and 1× PCR Master Mix (Fermentas).

\section{KCN I F (5' GGTATCCTAGTTATGGACTCAAT 3'), KCN I R (5' GTTGAAGTAACTTGGGCTGTGT $3^{\prime}$ ).}

The following conditions were used: an initial denaturation step of $95^{\circ} \mathrm{C}$ for 2 min was followed by 35 cycles of $94^{\circ} \mathrm{C}$ for $1 \mathrm{~min}, 59^{\circ} \mathrm{C}$ for $40 \mathrm{~s}$, and $72^{\circ} \mathrm{C}$ for $3 \mathrm{~min}$, and concluded with a final extension step of $72^{\circ} \mathrm{C}$ for 5 min using a PTC-0200 DNA Engine thermal cycler (MJ Research Inc., Waltham, MA).

SSCP. Six microliters of PCR product were added to $8 \mu \mathrm{l}$ of stop mix containing $0.05 \%$ of xylene-cyanole, $0.05 \%$ of bromophenol blue, and $0.02 M$ EDTA in deionized formamide. After heat denaturation of $95^{\circ} \mathrm{C}$ for 7 min, the samples were immediately chilled on ice and then run overnight $(16.30 \mathrm{~h})$ on $9.25 \%$ polyacrylamide gels with $1 \%$ glycerol (Penguin TM Dual Gel WaterCooled Electrophoresis System, OWL Scientific Inc., Woburn, MA) in $0.5 \times \mathrm{TBE}$ buffer at $275 \mathrm{~V}$ and $12^{\circ} \mathrm{C}$. Bands were visualized by silver staining (Bassam et al, 1991). 


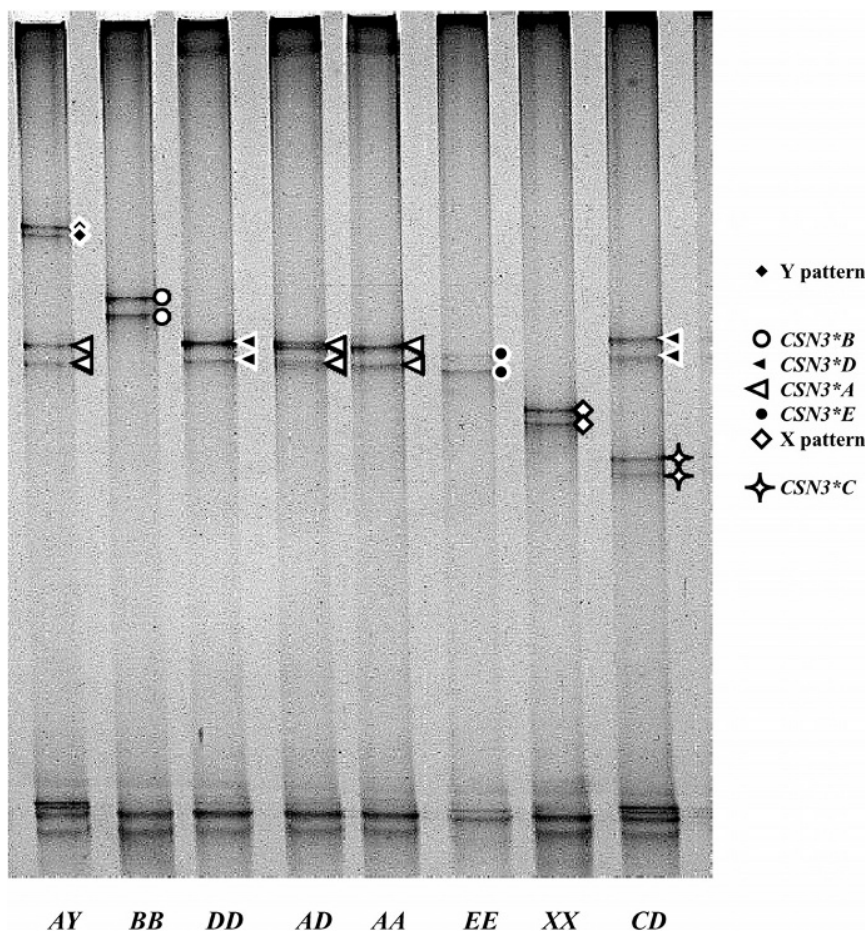

Figure 1. Polymerase chain reaction-single strand conformation polymorphism analysis of different $\kappa$-casein locus (CSN3) genotypes. Unknown migration patterns $\mathrm{X}$ and $\mathrm{Y}$ are also shown.

Isoelectrofocusing. Milk samples were analyzed by isoelectrofocusing (IEF) according to Caroli et al. (2001) for a comparison of the molecular results with the protein patterns.

Simultaneous discrimination of CSN3 alleles $A, B$, $C, D$, and $E$ was obtained by PCR-SSCP analysis (Figure 1). Two sets of bands, fast migrating and slow migrating, were present in duplication for each allele and were used for the genotype identification. Besides the five migration patterns related to the known variants, two further polymorphisms were found, preliminarily named $X$ and $Y$. Studies are in progress to identify the mutations responsible for these different patterns.

Beside $C S N 3{ }^{*} B$ allele, identifiable at protein level, $C S N 3^{*} A, C S N 3^{*} C, C S N 3^{*} D$, and $C S N 3^{*} E$ are clearly separated (Figure 1). By IEF analysis of milk samples, alleles $A, C$, and $D$ variants overlap. Thus, the molecular approach is necessary to type goats for CSN3 correctly to recognize mutations that could be related to a particular functional meaning as already demonstrated for CSN3 variants in cattle (Pagnacco and Caroli, 1987). In particular, the separation between the $A$ and $D$ variant is really important due to the small difference existing between the two variants: a substitution G/A at position 471, resulting in an amino acid exchange (Val/ Ile, position 119) not identifiable by IEF at the protein level. In fact, the monitoring of CSN3 variability in four domestic goat breeds performed by the technique developed clearly indicates the predominance of the $D$ allele, occurring with a frequency of $0.73,0.73,0.70$, and 0.63, respectively, in Garganica, Jonica, Maltese, and Camosciata breeds of goat (Table 2). The same variant, named $B$ according to the old nomenclature, was described by Yahyaoui et al. (2001) but could not be distinguished from the $A$ variant by the PCR-RFLP technique used, allowing the detection of the $C$ allele. A PCR-RFLP protocol was described for the detection of the $E$ allele (Angiolillo et al., 2002). In the Italian breeds genotyped in this study, no evidence was found for the $C$ and $E$ variants. More recently, a protocol for rapid simultaneous genotyping of CSN3 goat variants using the primer extension method has been described (Yahyaoui et al., 2003), and a nomenclature has been proposed still conflicting with the present paper as well as with Jann et al. (2003), who have detected further caprine CSN3 alleles. An effort has to be made at international level for full agreement about the nomenclature of such a polymorphic locus in goat.

The two further polymorphisms preliminarily named $X$ and $Y$, found in three of the four analyzed breeds but with a low frequency (less than $2 \%$ ), are also confounded with the $A / D$ variant group at protein level, whereas the $B$ variant typing corresponded both at the protein and DNA level.

Interestingly, $C S N 3 * A$ and $B$ occurred in different frequencies, ranging from $1.1 \%(C S N 3 * B$ in Camosciata) to $35.6 \%$ (CSN3*A in the same breed). In Garganica and Jonica, the two variants presented balanced frequencies. In a previous study, Caroli et al. (2001) described $C S N 3^{*} A$ as the most widely distributed allele in domestic goat breeds. However, the allele frequencies were determined at the protein level using IEF, which does not allow the separation of most variants from CSN3*A. Moreover, the PCR-SSCP analysis developed in the previous paper, using different primers, did not allow differences between $C S N 3{ }^{*} A$ and $\mathrm{CSN} 3 * \mathrm{D}$ to be determined. Therefore, the protocol presented here is indicated for the analysis of goat CSN3 polymorphisms.

The PCR-SSCP test used in this study is a rapid method to screen goat breeds at CSN3 locus. The use of this technique gives the opportunity to differentiate variants that are undistinguishable at protein level and to type animals independent of age, sex, and lactation. It also allows the identification of further alleles at the CSN3 locus. The demonstrated polymorphism at this locus must be carefully taken into consideration in addition to the already known variants at the other casein loci, in order to include casein haplotype information in breeding programs for the genetic improvement of domestic goat breeds. 
Table 2. Allele frequencies at $\kappa$-casein locus (CSN3) locus in the Garganica, Jonica, Maltese, and Camosciata breeds.

\begin{tabular}{lllll}
\hline & \multicolumn{4}{c}{ Allele frequency } \\
\cline { 2 - 5 } CSN3 variant & $\begin{array}{l}\text { Garganica } \\
(\mathrm{n}=34)\end{array}$ & $\begin{array}{c}\text { Jonica } \\
(\mathrm{n}=119)\end{array}$ & $\begin{array}{c}\text { Maltese } \\
(\mathrm{n}=105)\end{array}$ & $\begin{array}{l}\text { Camosciata } \\
(\mathrm{n}=45)\end{array}$ \\
\hline $\mathrm{A}$ & 0.132 & 0.136 & 0.086 & 0.356 \\
$\mathrm{~B}$ & 0.118 & 0.106 & 0.200 & 0.011 \\
$\mathrm{C}$ & - & - & 0.700 & 0.633 \\
$\mathrm{D}$ & 0.735 & - & - & - \\
$\mathrm{E}$ & - & 0.017 & 0.010 & - \\
$\mathrm{X}^{1}$ & - & 0.013 & 0.005 & - \\
$\mathrm{Y}^{1}$ & 0.015 & & & - \\
\hline
\end{tabular}

${ }^{1}$ Preliminary nomenclature.

\section{ACKNOWLEDGMENTS}

We are grateful to MURST contract 2001077279_002 and to VIGONI project for financial support, to EvaMaria Prinzenberg for valuable comments. We thank Antonella Angiolillo and Josep Maria Folch for $C S N 3{ }^{*} E$ and $C S N 3{ }^{*} C$ reference samples.

\section{REFERENCES}

Angiolillo, A., M. H. Yahyaoui, A. Sanchez, F. Pilla, and J. M. Folch. 2002. Characterization of a new genetic variant in the caprine $\kappa$-casein gene. J. Dairy Sci. 85:2679-2680.

Bassam, B.J., G. Caetano-Anollés, and P. M. Gresshoff. 1991. Fast and sensitive silver staining of DNA in polyacrylamide gels. Anal. Biochem. 196:80-83.

Budelli, E., P. Bolla, A. Caroli, S. Jäger, and G. Erhardt. 2000. Genetic polymorphism of goat k-casein. Pages $85-86$ in Proc. 27th Int. Conf. Animal Genetics, Minneapolis, MN.

Caroli, A., O. Jann, E. Budelli, P. Bolla, S. Jäger, and G. Erhardt. 2001. Genetic polymorphism of goat $\kappa$-casein (CSN3) in different breeds and characterization at DNA level. Anim. Genet. 32:226-230.

Coll, A., J. M. Folch, and A. Sanchez. 1993. Nucleotide sequence of the goat kappa-casein cDNA. J. Anim. Sci. 71:2833.

Di Luccia, A., R. Mauriello, L. Chianese, L., Moio, and F. Addeo. 1990. $\kappa$-Casein polymorphism in caprine milk. Sci. Tecn. Latt.Cas. 41:305-314.

Ferretti, L., P. Leone, and V. Sgaramella. 1990. Long range restriction analysis of the bovine casein genes. Nucleic Acids Res. 18:6829-6833.
Grosclaude F., G. Ricordeau, P. Martin, F. Remeuf, L. Vassal, and J. Bouillon. 1994. Du gène au fromage: Le polymorphisme de la caséine $\alpha_{\mathrm{s} 1}$ caprine, ses effets, son évolution. INRA Prod. Anim. 7:3-19.

Jann, O. C., E. M. Prinzenberg, G. Luikart, A. Caroli, and G. Erhardt. 2003. High polymorphism in the $\kappa$-casein (CSN3) gene from wild and domestic caprine species revealed by DNA sequencing. J. Dairy Res. (accepted).

Martin, P. 1993. Polymorphisme génétique des lactoprotéines caprines. Lait 73:511-532.

Mercier, J. C., F. Addeo, and J. P. Pelissier. 1976a Structure primaire du caséinomacropeptide de la caséine $\kappa$-caprine. Biochimie 58:1303-1310.

Mercier, J. C., J. M. Chaubert., and F. Addeo. 1976b. Comparative study of the amino acid sequences of the caseinomacropeptides from seven species. FEBS Lett. 1976: 208-214.

Pagnacco, G., and A. Caroli. 1987. Effect of casein and $\beta$-lactoglobulin genotypes on renneting properties of milks. J. Dairy Res. 54:479-485.

Prinzenberg, E. M., I. Krause, and G. Erhardt. 1999. SSCP analysis at the bovine CSN3 locus discriminates six alleles corresponding to known protein variants (A, B, C, E, F, G) and three new DNA polymorphisms (H, I, A1). Anim. Biotechnol. 10:49-62.

Threadgill, D. W., and J. E. Womack. 1990. Genomic analysis of the major bovine milk proteins genes. Nucleic Acids Res. 18:69356942.

Yahyaoui, M. H., A. Angiolillo., F. Pilla, A. Sanchez, and J. M. Folch. 2003. Characterization and genotyping of the caprine kappa casein variants. J. Dairy Sci. 86:2715-2720.

Yahyaoui, M. H., A. Coll, A. Sanchez, and J. M. Folch. 2001. Genetic polymorphism of the caprine kappa casein gene. J. Dairy Res. 68:209-216. 